\title{
0 que é que o reeleito tem? 0 retorno: o esboço de uma teoria da reeleição no Brasil
}

\author{
CARLOS PEREIRA E LUCIO RENNO*
}

W hat does the reelected have? The return: the outline of a reelection theory in Brazil. This article compares the determinants of electoral success in two consecutive Brazilian legislative elections, 1998 and 2002. There is a clear difference between both periods that renders the comparison especially interesting. In 1998 the incumbent president was running for reelection whereas in 2002 it was an open seat contest. We hypothesize that in 1998 the proximity of the Federal Deputy with the president and the allocation of federal monies controlled by the Executive Branch played a more significant role in affecting reelection success than in 2002. H ence, if the President is himself running for reelection is an important intervening contextual variable in understanding reelection success of Federal D eputies.

Key-Words: reelection, legislative elections, budgetary amendments.

Jel Classification: $\mathrm{H} 00$.

\section{INTRODUÇÃO}

O objetivo deste artigo é investigar os determinantes do sucesso eleitoral em duas el eições consecutivas para a Câmara dos Deputados, 1998 e 2002. É testado se o modelo desenvolvido para as eleições de 1998 (Pereira e R ennó, 2001 e 2003) também se aplica às eleições de 2002. 0 estudo comparado de duas eleições consecutivas aumenta a capacidade de produzir general izações sobre eleições legislativas no Brasil. Esse é um passo necessário, embora não suficiente, para consolidar uma teoria sobre sucesso el eitoral em um sistema proporcional com lista aberta, conjugado com uma extrema preponderância do executivo na arena legislativa.

\footnotetext{
* M ichigan State University - M SU. Escola de Economia de São Paulo - EESP/FG V. E-mail: carlospereira@fgvsp.br e University of A rizona. E-mail: Irenno@email.arizona.edu. Submetido: Fevereiro, 2006; aceito: A gosto, 2006.
} 
A princípio, há uma distinção clara entre esses dois episódios eleitorais. Em 1998, o Presidente concorria à reeleição. A proximidade do deputado com o executivo, bem como os mecanismos de transferências de benefícios e políticas locais controlados pelo Presidente, foram decisivos para o sucesso dos deputados que buscavam a reeleição em 1998. Já em 2002, não havia um candidato concorrendo à reeleição para Presidente. Isso poderia levar a uma redução do impacto do executivo nas eleições legislativas. O u seja, uma variável central em uma teoria sobre o sucesso eleitoral de Deputados Federais no Brasil é o fato do Presidente estar concorrendo à reeleição. Em tais circunstâncias, existe um maior impacto do Presidente nas chances de reeleição de deputados (presidential coattails effect). Já em el eições como a presidencial de 2002, consideradas pela literatura americana como open seat, em que não há candidato à reeleição, é esperado que 0 efeito do executivo sobre o futuro eleitoral dos legisladores candidatos à reeleição deve ser menor. ${ }^{1}$

A literatura sobre o impacto das eleições presidenciais em eleições para outros cargos no Brasil tende a minorar a influência do Presidente. A mes (1994) argumenta que há um efeito reverso, em que o apoio de prefeitos é fundamental para a vitória do candidato presidencial. Já Samuels (2000b) argumenta que o impacto de governadores é mais forte do que o de Presidentes. A mbas essas análises, contudo, foram desenvolvidas antes da mudança institucional que ocorreu no cenário político brasileiro; ou seja, a regulamentação do direito à reeleição para cargos do poder executivo. Portanto, nenhuma das duas abordagens permite a comparação entre uma situação onde a influência do Presidente pode ser mais acentuada. N osso estudo, portanto, testa o impacto do executivo no momento institucional presente e argumenta que a permissão da reel eição para Presidente afetou dramaticamente a forma como disputas el eitorais para o legislativo são conduzidas no Brasil. Estudos anteriores, apesar de sua contribuição teórica e metodológica, estão datados haja vista as mudanças institucionais recentes que ocorreram.

N ossa hipótese principal, portanto, é que variáveis que medem a influência do poder executivo federal nas chances de reel eição de Deputados Federais têm seu impacto condicionado pelas características da eleição presidencial, se open seat ou não. No primeiro caso, o impacto de variáveis que medem a relação entre o deputado e o Presidente deverá ser atenuado. Já quando o Presidente concorre à reel eição, sua influência sobre os parlamentares deve ser mais decisiva. Para testar essa hipótese, comparamos o impacto de um modelo explicativo idêntico do sucesso el eitoral de D eputados Federais em duas el eições consecutivas no Brasil, 1998 e 2002. Tal hipótese não foi testada anteriormente, pois, esta éa primeira tentativa sistemática de se comparar duas el eições consecutivas em um mesmo ambiente institucional com tais características no Brasil.

${ }^{1}$ Coattails, de forma literal, significa "rabo da casaca" . Em sentido figurado, significa que o Presidente puxa votos para os candidatos que 0 apóia. 
N as últimas quinze eleições ${ }^{2}$ para a Câmara dos D eputados no Brasil a maioria dos parlamentares se candidatou à reeleição, uma média de 68\% (ver tabela 1). D os deputados que optaram arriscar sua sobrevivência el eitoral concorrendo à reeleição, 67\% em média obtiveram sucesso em todos esses episódios el eitorais. Por outro lado, 33\% não alcançaram a mesma sorte ao amargaram derrotas diante da escolha de tentar permanecer no legislativo federal. Em outras palavras, a decisão pela ambição estática, ou seja, concorrer à reeleição, tem consistentemente proporcionado retornos eleitorais para a maioria dos parlamentares que a tentam.

Tabela 1

Taxa de Reeleição e Performance eleitoral no Brasil (1950-2002)

\begin{tabular}{llllllll}
\hline & Reeleição & $\%$ & Sucesso & $\%$ & Fracasso & $\%$ \\
\hline 1950 & 186 & 0,61 & 93 & 0,50 & 93 & 0,50 \\
\hline 1954 & 204 & 0,67 & 140 & 0,69 & 64 & 0,31 \\
\hline 1958 & 235 & 0,72 & 153 & 0,65 & 82 & 0,35 \\
\hline 1962 & 235 & 0,72 & 172 & 0,73 & 63 & 0,27 \\
\hline 1966 & 265 & 0,65 & 190 & 0,72 & 75 & 0,28 \\
\hline 1970 & 191 & 0,47 & 145 & 0,76 & 46 & 0,24 \\
\hline 1974 & 237 & 0,76 & 181 & 0,76 & 56 & 0,24 \\
\hline 1978 & 282 & 0,77 & 204 & 0,72 & 78 & 0,28 \\
\hline 1982 & 299 & 0,71 & 213 & 0,71 & 86 & 0,29 \\
\hline 1986 & 311 & 0,65 & 177 & 0,57 & 134 & 0,43 \\
\hline 1990 & 328 & 0,67 & 179 & 0,55 & 149 & 0,45 \\
\hline 1994 & 355 & 0,71 & 211 & 0,59 & 144 & 0,41 \\
\hline 1998 & 373 & 0,73 & 253 & 0,68 & 120 & 0,32 \\
\hline 2002 & 366 & 0,71 & 268 & 0,73 & 98 & 0,27 \\
\hline Média & 276,21 & 0,68 & 184,21 & 0,67 & 92 & 0,33 \\
\hline Fin & & & & & &
\end{tabular}

Fonte: Santos (2005), www.ucam.edu.br/leex/

0 objetivo deste artigo é examinar os determinantes do sucesso eleitoral dos Deputados Federais no Brasil. Pretende-se investigar o que o reel eito tem que os que não se reel egem não têm. Pereira e R ennó (2001 e 2003) propuseram um modelo analítico capaz de identificar os fatores que aumentam as probabilidades de

${ }^{2}$ Com exceção das eleições de 1970 quando a média de $47 \%$ dos deputados foram candidatos à reeleição. 
reel eição para a Câmara Federal nas eleições de 1998 no Brasil. Precisamente, foram testados dois conjuntos de hipóteses concorrentes que tentam explicar 0 sucesso eleitoral: o primeiro, que analisa o papel do sistema proporcional de lista aberta nas estratégias de sobrevivência el eitoral dos candidatos à reeleição; o segundo conjunto de hipóteses analisa o impacto das regras de funcionamento interno da Câmara dos deputados e os poderes do Presidente no comportamento do parlamentar dentro da Câmara.

Especificamente, o primeiro grupo é formado pelas variáveis que mensuram o impacto de aspectos políticos locais, ou seja, variáveis que se referem à atuação do candidato em assuntos diretamente relacionados com as suas bases el eitorais. Estas dizem respeito a distribuição de votos do candidato, ao grau de dominação e competição no principal reduto eleitoral, gastos de campanha, características do município, influência de políticas locais (pork barrel e credit claiming) e os padrões de coalizão com os atores políticos regionais e locais.

O segundo grupo de variáveis é formado pel os fatores políticos nacionais e diz respeito a sua participação e performance no Congresso e à influência do Presidente e dos partidos nas eleições para a Câmara. $\mathrm{O}$ u seja, se refere à participação do deputado na arena legislativa, sua posição na hierarquia da Câmara, identificação partidária e posição dentro da hierarquia do partido e, finalmente, 0 ef eito da influência do Presidente nas el eições legislativas.

Foi demonstrado nas eleições de 1998 que o sistema político brasileiro gera vários incentivos para que os el eitores se preocupem mais com os benefícios locais do que com a performance nacional dos seus representantes. Isto faz com que a participação dos parlamentares no espaço nacional, principalmente nas atividades dentro da Câmara dos D eputados, seja orientada pela busca de benefícios que possam ser utilizados no espaço local, como forma de alcançarem maiores retornos eleitorais. A distribuição de benefícios locais, assim, proporciona muito mais retornos el eitorais do que as atividades legislativas dentro da Câmara ou as posições de voto assumidas em relação a uma determinada política. É importante enfatizar que a participação do deputado no processo legislativo bem como seu perfil de voto no planário da Câmara dos Deputados não influiram diretamente nas suas chances de ser reeleito. $\mathrm{N}$ a realidade, os interesses locais prevalecem na arena eleitoral porque as demandas locais parecem ter impacto mais forte no sucesso eleitoral. M esmo o comportamento partidário, quando este acontece dentro da Câmara, segue esta lógica, pois são os líderes dos partidos e o executivo que controlam a distribuição de benefícios.

N este artigo, pretendemos re-visitar os nossos argumentos oferecidos na análise de um único episódio el eitoral comparando-se agora dois episódios el eitorais, 1998 e 2002. Ainda que o padrão predominante de carreira e de maior sucesso el eitoral venha sendo a ambição estática (reel eição), o ideal seria setivéssemos acesso a uma série histórica mais ampla que cobrisse de forma consistente o maior número de episódios el eitorais para testarmos a consistência e a robustez dessa teoria. A creditamos, entretanto, que a análise comparativa das últimas duas eleições no Brasil oferece evidências preliminares para a proposição de um esboço 
de uma teoria da reeleição em um ambiente institucional caracterizado por um sistema el eitoral extremamente permissivo, hiper-representativo e atomista, que combina representação proporcional com lista aberta associada a uma extrema preponderância do executivo na arena legislativa.

A comparação entre as el eições de 1998 e 2002 é especialmente interessante porque permite acrescentar um importante elemento explicativo à nossa teoria: as características da el eição presidencial. N ossa hipótese central, como já foi dito, é que a capacidade do Presidente de afetar os resultados das el eições legislativas é bastante reduzida quando o Presidente é um lame duck, quando não concorre à reel eição. $\mathrm{O}$ u seja, em el eições onde o Presidente não concorre à reeleição, variáveis que medem a relação do parlamentar com o poder executivo perdem poder explicativo do sucesso el eitoral dos deputados. Q uando um Presidente concorre à reel eição, parlamentares que o apóiam se beneficiam positivamente. Q uando isso não ocorre, a proximidade com o poder executivo não faz tanta diferença. O u seja, o impacto de certas variáveis do modelo original de Pereira e Rennó (2001 e 2003) é condicional às características da el eição presidencial; se esta é open seat ou não.

\section{Trabalhar em Brasília ou na base eleitoral: qual a melhor estratégia?}

Q ue fatores afetam o cálculo dos parlamentares sobre qual problema, assunto ou temática vale a pena alocar tempo, energia e recursos? Faz sentido um parlamentar se dedicar com mais intensidade às atividades legislativas internas da Câmara dos D eputados em Brasília (work horses) ou às questões relacionadas a sua base eleitoral (show horses)? Q ual a melhor estratégia para se obter sucesso eleitoral em um ambiente institucional em que o executivo é o principal legislador e onde o processo decisório é extremamente centralizado pelas lideranças partidárias e legislativas? A té que ponto votar com o Presidente no plenário da Câmara traz frutos eleitorais? E se o Presidente não for candidato à reeleição (lame-duck), apoiá-lo é a melhor estratégia para sobreviver eleitoralmente? Em outras palavras, que tipo de benefícios um $D$ eputado Federal que é candidato à reeleição pode extrair de um Presidente que está fora da próxima disputa eleitoral? Será que um deputado que beneficiou sua principal base eleitoral com emendas individuais ao orçamento federal terá recompensas eleitorais por seus esforços localistas? O u terão mais retornos el eitorais aqueles parlamentares que dispersarem benefícios orçamentários por todo o seu estado?

Estes são dilemas de difícil resolução. Possíveis pistas podem ser encontradas na análise dos benefícios e restrições oferecidos pelo conjunto de regras que regem tanto a forma de alocação e distribuição de poder na arena el eitoral, bem como as instituições que regem o processo decisório dentro da arena legislativa. Enquanto alguns ambientes institucionais geram mais incentivos para a profissionalização da atividade legislativa, outros oferecem mais restrições para que o parlamentar possa 
influenciar e afetar o que o legislativo produz, pois este terá mais incentivos para se dedicar aos problemas e questões das suas bases el eitorais.

A profissionalização funcionaria como um pré-requisito para o desenvolvimento de uma legislatura independente, representativa e competente. É a partir de dispositivos organizacionais gerados pela profissionalização que se criam e se desenvolvem condições de institucionalização de regras e procedimentos que incentivam a estabilização da carreira e das atividades parlamentares. Uma legislatura profissionalizada fornece incentivos à institucionalização, à estabilidade das regras de decisão, à especialização e mel hor acesso e circulação de informação, bem como independência do legislativo vis à vis o executivo. Políticos que exercem apenas um mandato parlamentar e depois se retiram do legislativo, provavelmente estão muito mais propensos a usufruir o cargo público em benefício particular. Portanto, estruturas parlamentares que estimulem a busca da reeleição podem diminuir a propensão à corrupção e aumentar a capacidade dos el eitores de punir os políticos que se desviem das suas preferências. A profissionalização do legislativo aumenta o interesse e a capacidade do parlamentar em buscar a reel eição e em procurar um maior engajamento nas atividades legislativas. A lém disso, quanto maior a extensão do horizonte temporal do parlamentar, maiores as chances de especialização e aperfeiçoamento dos deputados no exercício de suas funções legislativas.

Q uais incentivos à profissionalização são produzidos pelo sistema político brasileiro para que os parlamentares se sintam motivados a alocar tempo, recursos e energia no seu desempenho legislativo? 0 dilema do desenvolvimento de uma carreira nacional versus carreira local não é exclusivo do sistema político brasileiro. Trabalhos como o de Richard Fenno (1978) já analisaram o caso americano: Washington career versus home career. Ter uma carreira nacional significa ocupar posições de poder dentro do legislativo; de outro lado, o foco na dimensão local não pode ser perdido, pois também é necessária a manutenção e a sustentação da rede local (home network) do legislador. A pressão entre fazer crescer o poder exercido na esfera nacional sem perder espaço e importância no reduto el eitoral é o equilíbrio perfeito perseguido pelo legislador que se vê cotidianamente nesta encruzilhada.

No caso brasileiro, o exercício da atividade legislativa em Brasília sofre duas influências gravitacionais, uma exógena e outra endógena, em outras palavras, uma centrípeta e outra centrífuga. A primeira diz respeito particularmente à influência decisiva do executivo no dia a dia do Congresso. 0 Presidente não é apenas o principal legislador, mas também quem define a agenda legislativa ao determinar o ritmo e conteúdo do que é decidido. ${ }^{3} \mathrm{~N}$ o máximo, pode-se atribuir

\footnotetext{
${ }^{3}$ Pela primeira vez na história recente da democracia brasileira, o Presidente da república não foi capaz de eleger o seu candidato à presidência da $C$ âmara dos $D$ eputados, com a eleição do deputado Severino Cavalcanti (PP-PE). No pequeno intervalo de tempo em que o executivo ficou destituído desse instrumento de controle sobre a agenda legislativa, pôde experimentar o valor desse poder.
} 
um papel meramente reativo do legislativo no processo de formulação e de decisão de leis. Q uando o executivo se vê ameaçado em suas preferências, pode ainda dispor de uma série de outros mecanismos de controle e intervenção no processo legislativo como: pedido de urgência, ${ }^{4}$ veto parcial e total, execução discricionária do orçamento, etc.

A segunda influência, endógena, se refere à estrutura interna de alocação de competências e poderes no legislativo. A Câmara dos Deputados possui um alto grau de centralização em sua organização interna e seu processo decisório. A grande maioria dos parlamentares tem um papel apenas residual nas decisões que são tomadas em Brasília. $\mathrm{N}$ a realidade, este processo é extremamente concentrado nas mãos dos líderes partidários e da M esa Diretora da Câmara. As comissões permanentes da casa, arena onde os parlamentares poderiam ter uma maior influência na produção de leis, são extremamente desaparel hadas e sem mecanismos profissionais e institucionais eficazes para garantir as suas decisões vis à vis a dominância do plenário e do executivo. ${ }^{5} \mathrm{~N}$ a realidade, os parlamentares, por não terem mandato nas comissões, podem ser substituídos a qualquer momento pelos líderes das suas respectivas bancadas, diminuindo assim os incentivos à especialização e profissionalização.

Diante desse quadro de baixos incentivos e fortes restrições para desenvolvimento de uma carreira política baseada em atividades legislativas em Brasília, os caminhos para o sucesso el eitoral apontam na direção do reduto el eitoral. Usando a terminologia de Fenno (1978), o que importa para o sucesso eleitoral é desenvolvimento de uma home career. Como tornar visíveis as atividades internas da casa para potenciais eleitores se 0 ambiente institucional, no qual os parlamentares estão imersos, os convida a ficar, a maior parte do tempo, nas suas bases el eitorais?

\section{A influência do Presidente no sucesso eleitoral de $D$ eputados Federais à reeleição}

Sistemas políticos caracterizados por uma grande preponderância institucional e política do executivo nas atividades legislativas tendem a ter uma influência direta no sucesso eleitoral dos parlamentares. Como é amplamente sabido, o Pre-

\footnotetext{
${ }^{4} \mathrm{Q}$ uando um pedido de urgência é feito para uma proposta, a comissão tem somente duas sessões para examiná-lo e votá-lo antes de mandá-lo para o plenário. $\mathrm{N}$ a prática, este prazo é muito curto e as comissões dificilmente conseguem examinar e se posicionar em relação a uma proposta que tenha recebido um pedido de urgência. Em geral, quando o Legislativo pede urgência para uma proposta, isto é feito de acordo com os interesses do Executivo. A taxa de aprovação de uma legislação que tenha se originado no Executivo é altamente associada ao pedido de urgência (Pereira e M ueller, 2000).

${ }^{5}$ De maneira geral, é prerrogativa dos líderes dos partidos nomear, assim como substituir, a qualquer momento, os membros das comissões. $N$ ão existem restrições sobre o tempo de permanência dos deputados nas comissões. Existem evidências de que há uma significativa interferência por parte dos líderes dos partidos nesse processo. Há uma alta rotatividade dos membros nas comissões. O s deputados mudam de comissão freqüentemente, não só a cada novo ano legislativo, mas também dentro do ano. A lém disso, o Executivo, através dos líderes, manipula as nomeações de certas comissões para colocar nelas números estratégicos de membros fiéis aos seus interesses (Pereira e M ueller, 2003).
} 
sidente no Brasil exerce uma forte influência na agenda legislativa e, por conseqüência, em todo seu processo decisório. 0 executivo também pode emitir $M$ edidas Provisórias, iniciar nova legislação, legislar exclusivamente em matérias orçamentárias eadministrativas. Um dos componentes decisivos do domínio exercido pelo Executivo sobre o legislativo é o processo de execução das emendas individuais e coletivas dos deputados na Lei orçamentária aprovada pelo Congresso e sancionada pelo Presidente. ${ }^{6}$ Embora os deputados tenham o direito constitucional de formular e aprovar emendas ao projeto de lei previamente elaborado pelo executivo, é este último que executa este orçamento, pois o orçamento no Brasil é autorizativo e não mandatório. $\mathrm{N}$ a sua grande maioria, os parlamentares fazem uso dessa prerrogativa apresentando emendas individuais e coletivas com políticas cujo objetivo é beneficiar os municípios onde obtiveram maior número de votos na eleição anterior - suas bases eleitorais - como forma de maximizar suas futuras chances el eitorais.

0 executivo brasileiro tem, sistematicamente, se valido da não sincronização entre arrecadação efetiva e dispêndios previstos na Lei orçamentária para contingenciar a execução orçamentária em relação à disponibilidade de recursos ou para solicitar créditos adicionais. Isto caracteriza uma situação por demais privilegiada para o Executivo nas suas negociações com o Legislativo, uma vez que este dispositivo institucional lhe garante alto grau de discricionariedade e flexibilidade na execução do orçamento.

Existem fortes evidências (Pereira e M ueller 2002) de que o Executivo tem se utilizado do processo de execução das emendas na lei orçamentária para recompensar ou punir os parlamentares dependendo de suas performances. Em outras palavras, os parlamentares que votam consistentemente de forma favorável às preferências do Executivo têm maior probabilidade de verem executadas as suas emendas. Por outro lado, os parlamentares que se comportam consistentemente de forma contrária aos interesses do Executivo têm uma probabilidade menor de verem as suas emendas executadas.

D esta forma, apoiar o Presidente na Câmara pode permitir acesso a uma ferramenta extremamente importante para o sucesso el eitoral dos parlamentares. Este, inclusive, foi um dos principais achados que Pereira e R ennó demonstraram na análise dos determinantes do sucesso el eitoral nas eleições de 1998. Entre-

\footnotetext{
${ }^{6}$ Pereira e M ueller (2002) elaboram um modelo espacial onde explicam o uso estratégico da execução orçamentária por parte do Executivo para fazer valer suas preferências no Congresso $\mathrm{N}$ acional. Estes autores sugerem que, embora o custo para manter a sua coalizão disciplinada no Congresso não seja muito alto, estes recursos são de fundamental importância para a sobrevivência política dos parlamentares. É importante ressaltar, entretanto, que o executivo no Brasil dispõe de outros mecanismos de montagem e manutenção de sua maioria no Congresso como ministérios, cargos na burocracia, recursos não-orçamentários, transferências voluntárias federais para estados e municípios etc. Contudo, como a unidade de análise em nosso estudo é o deputado individual, a operacionalização desses outros mecanismos é impraticável já que não há registros oficiais que vinculem deputados individuais à alocação de tais recursos.
} 
tanto, como mencionamos anteriormente, nas eleições de 2002 o Presidente estava impedido constitucionalmente de concorrer a um terceiro mandato consecutivo. Logo, é plausível supor que a interferência do executivo nesse episódio eleitoral tenha sido menor do que em 1998, quando este era candidato à reeleição.

Portanto, as características do pleito para Presidente da R epública podem condicionar o impacto do modelo explicativo do sucesso eleitoral de Deputados Federais que concorrem à reeleição. A principal hipótese que será testada aqui é que as variáveis relacionadas à capacidade de influência do poder Executivo nas eleições legislativas terão impacto mais reduzido na sorte el eitoral dos Deputados Federais que concorrem à reeleição em 2002. Em 1998, com Fernando H enrique $\mathrm{C}$ ardoso competindo para a reeleição, ser um aliado do Presidente deve ter ajudado os deputados em sua busca pela reeleição.

Como mencionado anteriormente, existem pelo menos duas interpretações sobre o impacto eleitoral do Presidente e ambas afirmam que tal influência não é decisiva. Barry A mes (1994) sugere a existência de um efeito reverso do fenômeno chamado coattails. Para ele, a troca de apoio el eitoral de prefeitos por benefícios locais futuros é o fator primordial no sucesso el eitoral de candidatos a Presidente. Ele demonstra que os candidatos à presidência apresentaram melhor desempenho el eitoral nos municípios onde o prefeito era do mesmo partido. 0 u seja, não seriam os prefeitos os que se beneficiariam el eitoralmente ao se aproximar de um Presidente institucionalmente poderoso, mas sim o Presidente; daí o efeito reverso. Por outro lado, D avid Samuels (2000) argumenta que o sistema eleitoral brasileiro oferece fortes incentivos para que os candidatos a cargos no Legislativo federal organizem suas campanhas tendo como referência o candidato a governador do estado, ao invés do candidato a Presidente. Para ele o que existiria no Brasil seria um efeito coattail do governador, pois os candidatos ao legislativo obteriam maiores frutos eleitorais construindo alianças com " poderosos" governadores. As influências de partidos nacionais e do Presidente seriam assim minoradas.

Embora estas duas abordagens apontem para distintos atores que seriam fundamentais no jogo el eitoral no Brasil, prefeitos para A mes e governadores para Samuels, ambas compartilham da posição de que as principais forças eleitorais no Brasil seriam fundamentalmente locais e não nacionais. $\mathrm{O}$ u seja, a influência de forças nacionais tais como o Presidente ou partidos políticos seriam minoradas diante de um federalismo robusto e de regras el eitorais que aproximariam em demasia os legisladores de suas bases eleitorais.

Contudo, cabe destacar novamente algumas mudanças institucionais que ocorreram no Brasil. A primeira foi a permissão para concorrer à reeleição por um mandato consecutivo nos cargos eletivos do poder executivo. Um Presidente concorrendo à reeleição aumenta a chance de existência de um efeito coattails puxado pelo Presidente. Segundo, desde o primeiro mandato do Presidente Fernando $\mathrm{H}$ enrique $\mathrm{C}$ ardoso, governadores vem progressivamente perdendo poder. Uma outra mudança dramática foi a redução da capacidade de endividamento de governadores e prefeitos, através da privatização dos bancos estaduais e da implementação da Lei de R esponsabilidade Fiscal. Tais mudanças reduziram em muito a influência do poder executivo municipal e estadual em eleições legislati- 
vas federais. Por outro lado, aumentou ainda mais a influência de variáveis que mensuram a relação entre Presidente e D eputado Federal.

U m outro fator que também deve ser levado em consideração na caracterização da eleição presidencial é a popularidade do candidato à reeleição. Em 1998, Cardoso contava com altos índices de aprovação popular. Para se ter uma idéia, a avaliação positiva do Presidente Cardoso um mês antes da sua reeleição, setembro de 1998, era de $45 \%$ menor apenas do que no início de seu primeiro mandato, fevereiro de 1995, em plena efervescência do plano Real (ver Figura 1). Seria natural que a maioria dos parlamentares tivesse ainda mais interesse em se aproximar de um Presidente popular com o objetivo de extrair benefícios eleitorais.

Em 2002, entretanto, Cardoso já não mais desfrutava da alta popularidade. $\mathrm{N}$ a realidade, logo após ser reeleito, sua popularidade apresentou uma queda drástica, quando a sua avaliação positiva ficou abaixo de $10 \%$ em setembro e outubro de 1999. $\mathrm{N}$ a segunda metade de seu segundo mandato Cardoso apresentou uma pequena melhora na sua popularidade, entretanto, possivelmente não o suficiente para proporcionar impactos positivos nos seus aliados no Congresso. Q uatro meses antes das el eições, junho de 2002, a sua avaliação positiva conseguiu ultrapassar a negativa, mas ficou abaixo dos $30 \%$. Além do mais, 0 principal candidato da oposição, Lula, liderou de forma consistente as pesquisas de opinião durante toda campanha el eitoral, e o candidato da situação, J osé Serra, procurou diferenciar a sua candidatura não anexando sua imagem ao governo FHC. A participação do Presidente Cardoso no processo eleitoral para os candidatos a D eputado Federal foi assim muito pequena. Desta forma, os benefícios retirados da proximidade com o Presidente tiveram um impacto reduzido na sorte eleitoral dos que concorreram à reeleição em 2002.

Figura 1: Popularidade do Presidente Fernando Henrique Cardoso (1995-2002)

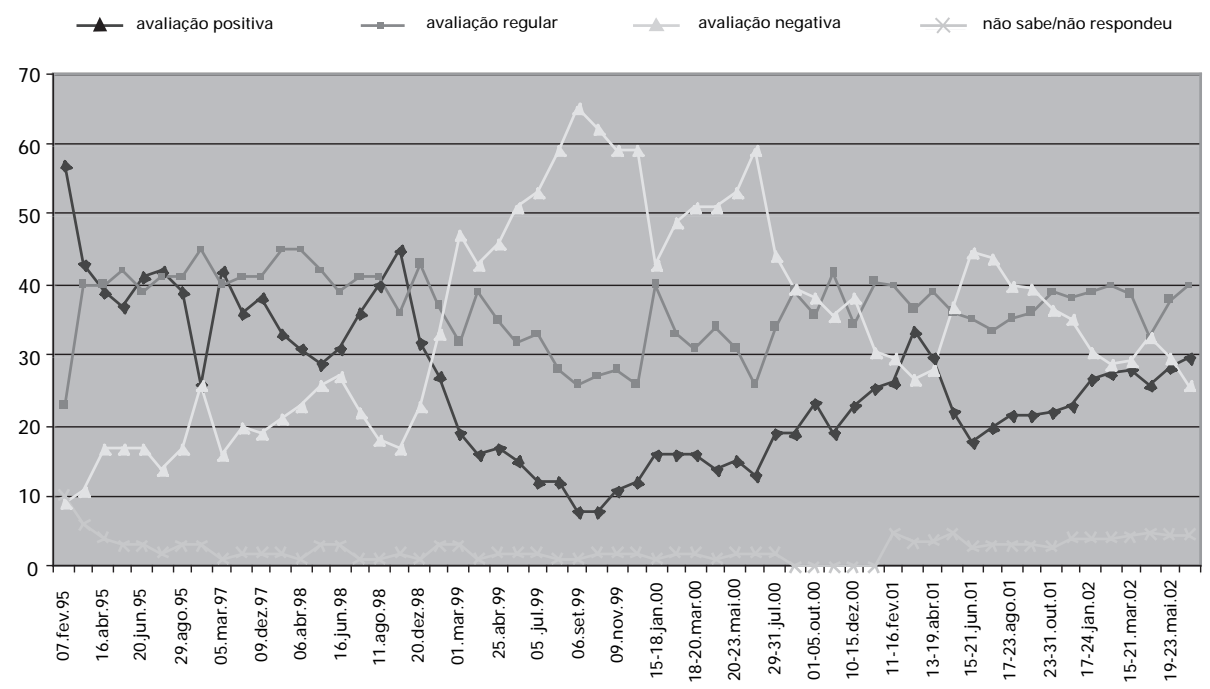


Em suma, nossa proposta de teoria sobre a reel eição de Deputados Federais leva em conta não apenas as características pessoais do candidato e da competição el eitoral em seu distrito, mas também o contexto mais amplo do ano el eitoral em que ocorre a eleição. D evido à centralidade do poder Executivo no Brasil, um elemento-chave é a eleição presidencial. Dessa forma, as variáveis que medem o impacto da proximidade do deputado com o Presidente deverão ter seu efeito atenuado no sucesso eleitoral de deputados quando as eleições presidenciais não apresentem um candidato à Presidente popular concorrendo à reeleição. No caso específico das eleições aqui analisadas, o efeito deve ser forte em 1998 e atenuado em 2002. ${ }^{7}$

\section{IVARIÁVEISE HIPÓTESES}

Este estudo contém variáveis que se referem à carreira do parlamentar em Brasília; que tratam das relações do parlamentar com a sua base eleitoral; e que se referem às características pessoais do parlamentar. $\mathrm{N}$ aturalmente, esta subdivisão segue um critério meramente analítico, pois algumas das variáveis contêm elementos que perpassam mais de um sub-conjunto. Um bom exemplo é a variável PORK (discutida abaixo) que, embora tenha um perfil marcadamente eleitoral, sua efetivação, no caso brasileiro, depende essencialmente das interações e trocas entre o executivo e legislativo.

\section{R elação com o Executivo}

No nosso modelo existem quatro variáveis-chave que estimam comparativamente o impacto do poder Executivo nas eleições legislativas de 1998 e 2002. A primeira diz respeito ao caráter contingenciado do orçamento federal e à discricionariedade do poder Executivo de executar ou não emendas orçamentárias. EM EN DAS é uma variável que mede a proporção das verbas executadas pelo poder Executivo das emendas individuais de cada deputado. A execução de emendas, conforme argumentam Pereira e M ueller (2003 e 2004) é componente central na formação e manutenção de maiorias no plenário da Câmara. Trata-se de um dos instrumentos de ganhos de troca que proporciona equilíbrio do jogo entre Executivo e Legislativo. Em outras palavras, o Presidente ganharia apoio dos deputados às propostas de interesse do executivo na Câmara e os parlamentares seriam recompensados com a execução de suas demandas específicas no orçamento. Portanto, execução de emendas é uma indicação da proximidade do parlamentar com o Executivo.

\footnotetext{
${ }^{7}$ É interessante especular o que pode acontecer nas eleições de 2006, com um candidato à reeleição para Presidente. Contudo, tal teste só será possível quando os dados estiverem disponíveis.
} 
Uma outra forma de estimar o impacto do Executivo no sucesso el eitoral é através da distribuição de benefícios particularizados na principal base eleitoral do parlamentar, PORK. Esta variável indica o valor em Reais do total das emendas executadas no município onde o parlamentar recebeu maior número de votos na el eição anterior. N ossa hipótese em relação as variáveis EM EN D AS e PO RK é que elas afetam positivamente as chances de reel eição.

A terceira variável que mensura a relação entre o deputado e o Presidente é PARTIDO DO GOVER N O, que indica se o parlamentar pertence a um partido da base de sustentação do governo. Por último, A POIO AO PRESIDENTE representa um índice que mede o comportamento favorável às propostas do interesse do Presidente no plenário da Câmara dos Deputados.

N ossa expectativa é a de que, em 1998, essas variáveis tenham um impacto estatisticamente significativo e positivo com relação às chances de reel eição de Deputados Federais, devido à popularidade do Presidente FH C e ao fato dele estar participando ativamente em busca de sua própria reel eição. Já em 2002, a ausência de FHC e sua baixa popularidade levam a uma diminuição do impacto das variáveis que medem a proximidade do deputado ao Presidente. Aliado a isso, o vigor de uma candidatura de oposição ao Presidente (Lula) atenuou as chances dos seus aliados nas eleições legislativas. A famosa "onda vermelha" que varreu o país em 2002 e tornou o PT o maior partido na Câmara dos Deputados, por si só reduziu as chances de reeleição de candidatos governistas. Sendo estes os que mais se beneficiariam da proximidade com o Presidente, é razoável supor que as variáveis desse grupo não tenham tido o mesmo impacto verificado em 1998. Conseqüentemente, esperamos que essas variáveis vinculadas ao Presidente não devem ter impacto estatisticamente significativo em 2002.

\section{Performance nos partidos políticos}

Este conjunto de variáveis está relacionado à performance do parlamentar dentro do seu partido político. Já que as regras el eitorais não punem a troca de partido e os partidos não possuem poder sobre os mandatos dos seus parlamentares, mudanças de partido são uma prática comum entre parlamentares brasileiros. Assim, nós operacionalizamos a variável N ÚM ERO DE M UDAN ÇAS de partido de um parlamentar durante cada um dos mandatos. Se nós assumirmos que o partido político exerce algum papel informacional aos seus potenciais eleitores facilitando uma maior identificação dos seus candidatos, mudar de partido deve ter um impacto negativo no sucesso el eitoral.

D ecidimos também controlar pela posição hierárquica do parlamentar dentro do seu partido. POSIÇÃO N O PARTIDO é uma variável dicotômica com o valor de 1 se o parlamentar exerceu uma posição de liderança no partido durante 0 seu mandato. Como os líderes partidários são figuras de destaque e ocupam mais espaço de visualização e identificação dos el eitores, esperamos uma correlação positiva com sucesso el eitoral. Além disso, os líderes partidários, principalmente aqueles que fazem parte da coalizão de governo, têm um papel fundamental ao negociarem as demandas dos seus liderados junto ao executivo. 


\section{Performance na Câmara dos D eputados}

N este bloco, incluímos no modelo um conjunto de variáveis que se referem ao desempenho dos candidatos dentro da Câmara. Pretendemos testar se ocupar posições hierárquicas nas atividades da casa exercem um impacto no sucesso eleitoral, pois tais posições aumentam a visibilidade do parlamentar nos meios de comunicação bem como permite um maior acesso a recursos para os que as ocupam. Fazem parte da equação as seguintes variáveis: M ESA DIRETO RA, CO M ISSÃO PERM ANENTE, COM ISSÃO ESPECIAL E RELATOR DE COM ISSÃ $O$. Todas elas são variáveis dicotômicas com o valor de 1 se o parlamentar exerceu uma dessas funções.

Também incluímos as variáveis HIST Ó RICO LEGISLATIVO e HIST ÓRICO EXECUTIVO para designar o número de experiências prévias dos parlamentares em outras esferas legislativas e/ou executivas. SÊN IO R indica o número de mandatos anteriores exercidos pelo parlamentar na Câmara Federal. Por último, incluímos a variável PROJETOS que indica o número de projetos de lei que foram propostos pelo parlamentar e aprovados pelo plenário da Câmara. Esperamos que essas variáveis tenham um impacto reduzido no sucesso eleitoral devido à dificuldade e alto custo de monitoração dos eleitores em relação às atividades legislativas.

\section{Variáveis eleitorais}

Incluímos quatro variáveis estritamente relacionadas à performance el eitoral dos parlamentares nas duas últimas eleições. A primeira variável é V OTAÇÃ O, que indica o total de votos que o parlamentar recebeu na eleição anterior. Esta variável é uma medida de segurança eleitoral do parlamentar e por isso esperamos que esta tenha um impacto positivo na probabilidade de sucesso eleitoral. O u seja, quanto maior a quantidade de votos obtidos no último episódio eleitoral, maiores as chances do parlamentar se reeleger, pois ele já desfrutaria de uma quantidade sólida de eleitores.

CON CENTRAÇÃ O eleitoral é uma variável que estaria mais diretamente relacionada ao padrão de distribuição espacial de votos no estado. 0 total de votos obtidos no município no qual o candidato teve mais votos é dividido pelo total de votos que ele obteve em todo estado. Logo, essa variável estima em que medida estratégias de concetração/dispersão de votos ajudam o candidato a se reel eger. É previsto uma correlação negativa entre concentração de votos e sucesso eleitoral. Parlamentares com alta concentração de votos tendem a ser mais vulneráveis eleitoralmente com relação possíveis competidores. Por outro lado, parlamentares que obtêm votos de forma dispersa por todo o distrito eleitoral tentem a ser menos vulneráveis, pois mesmo diante da presença de fortes competidores em alguns redutos estes ainda teriam condições de ser bem votados em outros municípios.

Também incluímos no modelo uma medida de competição eleitoral no reduto eleitoral do parlamentar, M ÉDIA DE CANDIDATOS. Espera-se que quanto maior o número de candidatos que disputam votos no estado do parlamentar, maior será 
a competição e, conseqüentemente, mais difícil será a sua reeleição. Por outro lado, quanto menor o número de competidores, maior a probabilidade de reeleição.

A última variável el eitoral no modelo é GASTO DE CAM PAN H A, que representa o total de gastos que foram declarados pelo candidato ao Tribunal Superior Eleitoral (TSE) nas duas eleições. É senso comum considerar-se a probabilidade de vitória el eitoral como uma função dos gastos de campanha. Samuels (2002) argumenta que esta é a variável central para explicar sucesso eleitoral no Brasil.

\section{Características pessoais}

D ecidimos controlar por algumas características pessoais como, por exemplo, o fato do parlamentar ter se candidatado a PREFEITO nas eleições de 1996 e 2000. M esmo perdendo as eleições para prefeito, os parlamentares não perdem seus mandados de Deputado Federal. É possível supor que vários parlamentares optem por concorrer a Prefeito como uma estratégia para manter seus nomes em evidência, aumentando assim as suas chances à reel eição como Deputado Federal. Por último, controlamos por agrupamento profissional do deputado como, por exemplo, ser empresário. D esta forma, EM PRESÁ RIO é uma variável dicotômica com o valor de 1 se o parlamentar se auto-identifica com esta denominação profissional em seus currículos. Esperamos que essa apresente um coeficiente positivo e estatisticamente significante para as eleições de 1998, dado que a coligação do Presidente Fernando $\mathrm{H}$ enrique $\mathrm{C}$ ardoso teve um perfil marcadamente de centrodireita com uma maior presença desta categoria profissional. Por outro lado, esperamos o efeito inverso nas el eições de 2002, pois o contexto eleitoral de forte oposição ao governo Cardoso favorecia outras categorias profissionais.

\section{AN ÁLISE DOSRESULTADOS}

O s dados utilizados para a análise foram coletados através de pesquisa em arquivos do Tribunal Superior Eleitoral e da Câmara dos Deputados. A unidade de análise é o deputado individual que assumiu o mandato, seja como titular seja como suplente, nas legislaturas de 1998 (50a legislatura) e de 2002 (51aㅣ legislatura). É importante ressaltar que a inclusão de suplentes é fundamental para evitar vieses de seleção na amostra. Há alguns suplentes que exerceram o mandato por mais tempo do que alguns titulares. Tais suplentes têm acesso a todos os benefícios do cargo e excluí-los da amostra seria incorrer em viés de seleção. Do mesmo modo, incluir alguns suplentes e não outros, baseado no período de exercício do mandato, tampouco é justificável e poderia enviesar os resultados. A final, nosso objetivo é avaliar a performance el eitoral daqueles que tiveram acesso aos benefícios do cargo. Contudo, o modelo inclui distinções entre suplentes e titulares através de uma variável que mede a porcentagem do tempo total de mandato que cada parlamentar exerceu. ${ }^{8}$

\footnotetext{
${ }^{8}$ Seguimos a sugestão de Samuels (2002), que argumenta que titulares têm maiores chances de serem
} 
0 modelo abaixo é estimado usando técnicas de máxima verossimilhança e a variável dependente é modelada seguindo uma distribuição probit. O s coeficientes indicam como a mudança de uma unidade nas variáveis independentes altera a probabilidade prevista de sucesso el eitoral. As variáveis independentes, por sua vez, foram todas centralizadas na média do estado de cada candidato, já que a competição direta do parlamentar se dá com outros membros de sua bancada estadual.

Tabela 2

Probit de Sucesso Eleitoral à Reeleição para Deputado Federal (1998 e 2002)

\begin{tabular}{|c|c|c|c|c|}
\hline \multirow{3}{*}{ 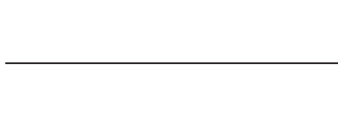 } & \multirow{2}{*}{\multicolumn{2}{|c|}{1998}} & \multirow{2}{*}{\multicolumn{2}{|c|}{2002}} \\
\hline & & & & \\
\hline & Coeficiente & $\begin{array}{c}\text { Erro Padrão } \\
\text { Robusto }\end{array}$ & Coeficiente & $\begin{array}{c}\text { Erro Padrão } \\
\text { Robusto }\end{array}$ \\
\hline $\begin{array}{l}\text { Controlando por Titular } \\
\text { Titular } \\
\text { Dias }\end{array}$ & $\begin{array}{l}.104 \\
-.031\end{array}$ & $\begin{array}{l}.073 \\
.109\end{array}$ & $\begin{array}{l}.109 \\
-.082\end{array}$ & $\begin{array}{l}.108 \\
.114\end{array}$ \\
\hline $\begin{array}{l}\text { Variáveis Eleitorais } \\
\text { Votação } \\
\text { Concentração } \\
\text { Gastos de Campanha } \\
\text { Média de Candidatos }\end{array}$ & $\begin{array}{l}.000 * * * \\
-.274 * * \\
.000 * \\
-.015\end{array}$ & $\begin{array}{l}.000 \\
.116 \\
.000 \\
.012\end{array}$ & $\begin{array}{l}.000^{* * *} \\
-.334^{*} \\
.000 \\
-.018^{*}\end{array}$ & $\begin{array}{l}.000 \\
.166 \\
.000 \\
.010\end{array}$ \\
\hline $\begin{array}{l}\text { Performance nos Partidos } \\
\text { N. Mudanças } \\
\text { Posição no Partido }\end{array}$ & $\begin{array}{c}-.083 * \\
.041\end{array}$ & $\begin{array}{l}.036 \\
.052\end{array}$ & $\begin{array}{c}-.034 * * \\
.0296\end{array}$ & $\begin{array}{l}.016 \\
.0467\end{array}$ \\
\hline $\begin{array}{l}\text { Relação com o Executivo } \\
\text { Apoio ao Presidente } \\
\text { Emendas } \\
\text { Pork } \\
\text { Partidos do Governo }\end{array}$ & $\begin{array}{l}.010 \\
.249 * \\
.047 \\
.096 *\end{array}$ & $\begin{array}{l}.092 \\
.169 \\
.088 \\
.059\end{array}$ & $\begin{array}{l}-.003 \\
.006 \\
-.084 \\
.030\end{array}$ & $\begin{array}{l}.202 \\
.106 \\
.198 \\
.049\end{array}$ \\
\hline $\begin{array}{l}\text { Performance na Câmara } \\
\text { Sênior } \\
\text { Mesa Diretora } \\
\text { C. Permanente } \\
\text { C. Especial } \\
\text { Hist. Legislativo } \\
\text { Hist. Executivo } \\
\text { Relator de Com. } \\
\text { Projetos }\end{array}$ & $\begin{array}{c}-.029 \\
.026 * \\
.018 \\
-.037 * * \\
.012 \\
-.047 \\
-.001 \\
.050 \\
\end{array}$ & $\begin{array}{l}.028 \\
.015 \\
.017 \\
.013 \\
.057 \\
.063 \\
.001 \\
.062 \\
\end{array}$ & $\begin{array}{l}.008 \\
.041 \\
-.011 \\
-.004 \\
.082 \\
.081 \\
.000^{*} \\
.161^{*}\end{array}$ & $\begin{array}{l}.020 \\
.027 \\
.024 \\
.015 \\
.056 \\
.052 \\
.000 \\
.096\end{array}$ \\
\hline $\begin{array}{l}\text { Característica Pessoal } \\
\text { Empresário } \\
\text { Prefeito }\end{array}$ & $\begin{array}{l}-.081 \\
.053\end{array}$ & $\begin{array}{l}.062 \\
.065\end{array}$ & $\begin{array}{c}-.181 * * \\
.023\end{array}$ & $\begin{array}{l}.065 \\
.094\end{array}$ \\
\hline $\mathrm{N}$ & 404 & & 425 & \\
\hline Pseudo R-quadrado & 0.145 & & 0.1209 & \\
\hline
\end{tabular}

Significância estatística: * significa valor-P $<0.1$; ** valor-P $<0.05 ; * * *$ valor-P $<0.001$.

reeleitos que suplentes e controlamos pelo impacto estatístico de ser titular e de passar mais tempo na Câmara durante um único mandato. 
O s resultados confirmam nossas expectativas. Em 1998, a proximidade com o Presidente teve impacto central no sucesso el eitoral de candidatos à reeleição. Q uanto maior a execução orçamentária, bem como o fato de ser membro de um partido da base de sustentação do governo, tiveram impacto positivo e estatisticamente significativo nas chances de vitória eleitoral do Deputado Federal candidato à reel eição. Já em 2002, nenhuma dessas variáveis foi estatisticamente significativa. Além da proximidade com o Executivo em 1998, outras variáveis que afetam o sucesso eleitoral de D eputados Federais são os padrões de votação do candidato no estado (concentração), sua votação anterior, gastos de campanha e número de mudanças de partido. Q uem gastou mais, obteve mais votos na el eição anterior, concentrou menos votos e mudou menos de partido, tem maior chance de ser reeleito. Já em 2002, padrão semel hante se repete com relação às variáveis locais: quem teve mais votos na eleição passada tem maiores chances de ser reeleito, assim como quem concentra menos seus votos em um único município. Também quem mudou mais de partido ficou prejudicado nas eleições em $2002 .{ }^{9}$

As principais diferenças entre esses dois episódios eleitorais indicam que quem enfrentou menos competição em todo o estado em 2002 teve mais chance de ganhar as el eições, assim como quem teve mais projetos aprovados na Câmara. Empresários também tiveram suas chances reduzidas em 2002 e o gasto de campanha teve seu impacto atenuado.

Votar a favor dos interesses do executivo na Câmara, por sua vez, não teve qualquer impacto no sucesso eleitoral em nenhum das duas eleições. $\mathrm{N}$ a Tabela 3 é possível verificar que o impacto dessa variável se dá de forma indireta, ao afetar a liberação de verbas orçamentárias. Por isso, seu impacto direto é atenuado quando ambas são colocadas simultaneamente no modelo.

Tabela 3

Regressão Linear de Mínimos Quadrados da Execução de Emendas Orçamentárias (1998 e 2002).

\begin{tabular}{l|l|c}
\hline & 1998 & 2002 \\
\hline Gastos de Campanha & .000 & .000 \\
\hline Votação & .000 & .000 \\
\hline Concentração & $-.256^{* * *}$ & 081 \\
\hline Sênior & -.008 & $.032^{* *}$ \\
\hline Dias & $.578^{* * *}$ & $.138^{* *}$ \\
\hline Apoio ao Presidente & $.306^{* * *}$ & .143 \\
\hline Constante & $.367^{* * *}$ & $.189^{* * *}$ \\
\hline
\end{tabular}

Significância estatística: * significa valor-P $<0.1$; ** valor-P $<0.05$; *** valor-P $<0.001$.

\footnotetext{
${ }^{9}$ Esse resultado difere de nossos achados anteriores referentes apenas a 1998 (Pereira e Rennó 2001). $\mathrm{N}$ aquela ocasião, mudança de partido não tinha um impacto significativo no sucesso eleitoral. A razão para a diferença dos resultados é que no modelo anterior tínhamos uma variável que media a direção da mudança de partido, se saindo ou entrando na coligação de apoio do Presidente. N esse caso, essa variável se mostrava significativa, indicando que aqueles que deixavam a coligação do Presidente eram punidos. Infelizmente não temos esta variável para as eleições de 2002.
} 
A tabela 3 mostra a execução de emendas orçamentárias no estado (EM EN DAS) como variável dependente em uma regressão linear de mínimos quadrados. 0 teste estatístico indica que quanto maior o número de dias que o deputado exerce o mandato aumenta a probabilidade de execução de suas emendas. Por outro lado, quanto mais o deputado concentra votos em seu reduto el eitoral, menos emendas individuais são executadas. A mesma tabela também aponta para uma diferença importante entre as eleições de 1998 e de 2002: 0 impacto do índice de apoio às propostas do executivo. Em 1998, a significância estatística da variável "A poio ao Presidente" indica que votar de acordo com as preferências do Presidente aumentou e muito a chance do deputado ver executadas as suas emendas individuais. Já em 2002, esse impacto não é significante e bem menor substantivamente. O u seja, para as el eições de 2002 não houve um critério tão nítido do Presidente na alocação de emendas recompensando mais aqueles que 0 apoiaram. Esse resultado sugere que o Executivo, em el eições quando o Presidente não concorre à reel eição, perde importância no cenário L egislativo, tornandose, de fato, um lame duck. A relação entre o Executivo e o Legislativo no segundo mandato de Cardoso, principalmente em seus dois últimos anos de governo, foi muito mais atribulada do que no primeiro mandato, quando a sua coalizão foi mais estável.

Cabe enfatizar que a média geral de execução de emendas individuais na $50^{\underline{a}}$ Legislatura foi de $37 \%$ enquanto que na 51 a foi de $19 \%$, como é demonstrado pela constante na tabela 3. Portanto, no primeiro mandato de Fernando H enrique Cardoso, deputados tiveram mais sucesso em executar suas emendas do que no segundo. Esta diminuição de execução de emendas individuais talvez explique a perda de poder explicativo desta variável no sucesso eleitoral dos parlamentares que concorreram à reeleição, bem como também ajuda a entender o impacto reduzido do executivo nas eleições de 2002.

Por fim, vale ressaltar que nosso argumento não nega a importância do impacto do Presidente e da relação entre deputado e Presidente nas el eições legislativas brasileiras. Sugerimos apenas que esse impacto é condicional às características da eleição presidencial, que no Brasil variam de uma eleição para outra. Chamamos a atenção para duas características dessas eleições que podem afetar o impacto de variáveis que mensuram a relação entre Presidente e D eputado Federal: se há um candidato que concorre à reeleição para Presidente e se esse candidato goza de apoio popular. Q uando isso ocorre, o impacto da relação Presidente-deputado é marcadamente mais acentuado. A tabela 4 mostra os dois períodos e indica que o efeito da média da execução orçamentária é estatisticamente significante quando ambos os períodos são combinados, o que confirma achados anteriores (Pereira e Renno, 2003 e A mes, 1995). O u seja, esta variável apenas tem seu efeito atenuado em momentos el eitorais onde o Presidente se ausenta do processo eleitoral, comprovando assim a principal hipótese deste artigo. 
Tabela 4

Probit de Sucesso Eleitoral à Reeleição para

Deputado Federal (amostra combinada de 1998 e 2002)

\begin{tabular}{lc}
\hline Variáveis & Concorrer a Reeleição \\
\hline Controlando por Titular & $0.11^{*}$ \\
Titular & -0.05 \\
Dias & \\
\hline Variáveis Eleitorais & 0.000 \\
Gastos de Campanha & $0.001^{* * *}$ \\
Votação & $-0.33^{* * *}$ \\
Concentração & $-0.02^{* *}$ \\
Média de Candidatos & \\
\hline Performance nos Partidos & $-0.05^{* *}$ \\
Número de Mudanças & 0.03 \\
Posição no Partido & -0.02 \\
\hline Relação com o Executivo & $0.16^{*}$ \\
Apoio ao Presidente & 0.03 \\
Emendas & 0.05 \\
\hline Pork & \\
\hline Partido do Governo & -0.01 \\
\hline Performance no Congresso & $0.03^{* *}$ \\
Sênior & 0.006 \\
Mesa Diretora & -0.01 \\
C. Permanente & 0.000 \\
C. Especial & 0.06 \\
Relator de comissão & 0.03 \\
Projetos & -0.04 \\
\hline Variáveis de Controle & 829 \\
Prefeito & \\
Empresário & Ano eleitoral - 2002 \\
\hline $\mathrm{N}$ & \\
\hline Pseudo & \\
\hline
\end{tabular}

CONCLUSÃO

Testamos se as características das eleições presidenciais condicionam o impacto de diversos fatores na sorte eleitoral de D eputados Federais que concorrem à reel eição. Q uando o Presidente é um lame duck, sua capacidade de afetar eleições legislativas é reduzida. Em eleições como as de 2002, há mais espaço para outros fatores nacionais quando estes são comparados com indicadores que mensuram diretamente a proximidade com o poder Executivo como, por exemplo, investir na aprovação de projetos no Congresso. Já nas eleições de 1998, com um 
Presidente popular e candidato à reeleição, os deputados que o apoiaram se beneficiaram eleitoralmente dessa proximidade com o poder Executivo, tendo mais acesso a recursos.

Evidências apresentadas mostram que a capacidade do executivo de influenciar el eições legislativas varia e depende fundamentalmente das características particulares das eleições presidenciais. A conexão eleitoral brasileira é condicionada pelo executivo, mas o impacto deste último varia de acordo com as características daquele que exerce o cargo: Presidentes populares e diretamente envolvidos no processo eleitoral aumentam as chances de reeleição de seus aliados na Câmara. $\mathrm{N}$ a ausência de um Presidente com essas características, outros fatores, principalmente referentes à competitividade das eleições legislativas, passam a ser ainda mais influentes no sucesso el eitoral dos parlamentares candidatos à reeleição. Portanto, uma teoria sobre reeleição para D eputados Federais no Brasil deve também levar em consideração as características das eleições presidenciais.

\section{REFERÊN CIAS BIBLIOGRÁFICAS}

A mes, Barry. "Electoral Strategy under O pen-List Proportional Representation". A merican J ournal of Political Science 39 (2): 406-433, 1995.

"Electoral Rules, Constituencies Pressures, and Pork Barrel: Bases of Voting in the Brazi-

lian Congress." The Journal of Politics 57 (2): 324-343, 1995a. . The D eadlock of D emocracy in Brazil A nn Arbor: The University of M ichigan Press, 2001.

"The R everse Coattails Effect: Local Party Organization in the 1989 Brazilian Presidential

Election." American Political Science Review 88 (1): 95-111, 1994.

A morim N eto, O ctavio; Gary Cox; e M athew M cCubbins, "A genda Power in Brazil's Camara dos Deputados, 1989 to 1998". World Politics, 55 (4): 550-578, 2003.

Bickers, Kenneth e Stein, Roberts "The Electoral Dynamics of the Federal Pork Barrel". A merican J ournal of Political Science, 40 (4): 1300-1326, 1996.

Carson, Jamie, "Strategy, Selection and Candidate Competition in H ouse and Senate Elections". The Journal of Politics, 67 (1): 1-66, 2005.

Carson, Jamie e Roberts, Jason, "Strategic Politicians and U.S. H ouse Elections, 1874-1914". The Journal of Politics, 67 (2): 2005.

Crisp, Brian F., e Ingall, Rachael E. "Institutional Engineering and the $\mathrm{N}$ ature of Representation: $M$ apping the Effects of Electoral R eform in Colombia". A merican Journal of Political Science 46 (4): 733-48, 2002.

Figueiredo, Argelina e Limongi, Fernando, Executivo e L egislativo na N ova O rdem Constitucional. São Paulo: FGV Press, 1999.

Fenno, Richard. H ome Style: H ouse M embers in Their D istricts. Boston: Little, Brown and Company, 1978.

H all, Richard e Van H ouweling, R obert. "Avarice and A mbition: Representatives' Decisions to Run for or R etire from the U.S. H ouse". A merican Political Science Review, 89 (1): 121-136, 1994.

$\mathrm{H}$ all, Richard. Participation in Congress N ew H aven: Yale University Press 1996.

H ibbing, John R. "Legislative Careers: Why and how we should Study them." L egislative Studies Q uarterly, 24 (2): 149-171, 1999.

Kernell, Samuel. "To Stay, To Q uit, or to M ove Up: Explaining the Growth of Careerism in the H ouse of Representatives, 1878-1940." Paper presented at the A merican Political Science A ssociation M eeting, Philadelphia-PA. August 28-31, 2003.

Jacobsen, Gary C. The Politics of Congressional Election Boston: Little, Brown and Company, 1983. 
Kiewiet, D. Roderick e Z eng, Langche. "An A nalysis of Congressional Career Decision, 1947-1986." The A merican Political Science Review, 87 (4): 928-941, 1993.

Kinzo, M aria D'Alva. "Partidos, Eleições e Democracia no Brasil pós-1985". Revista Brasileira de Ciências Sociais, 19: 23-40 2004.

Leoni, Eduardo, Carlos Pereira; e Lucio Renno. "Political Survival Strategies: Political Career Decisions in the Brazilian Chamber of Deputies." Journal of Latin A merican Studies, 36 (1): 109$130,2004$.

Lodge, M .; M cGraw, K .; e Stroh, P. "An Impression-Driven M odel of Candidate Evaluation". A merican Political Science Review, 83: 399-419, 1989.

Lodge, M ., Steenbergen, M . e Brau, S. "The Responsive Voter: Campaign Information and the Dynamics of Candidate Evaluation". A merican Political Science Review, 89: 309-26, 1995.

Lupia, Arthur e M cC ubbins, M athew. The D emocratic Dilemma: Can Citizens Learn What They N eed to Know? Cambridge: Cambridge University Press, 1998.

$M$ ainwaring, Scott P. R ethinking Party Systems in the Third Wave of D emocratization. Stanford: Stanford University Press, 1999.

M ayhew, David, Congress: The Electoral Connection. N ew H aven: Yale University Press 1974.

M eneguello, Rachel, "Partidos e Tendências de Comportamento: O Cenário Político em 1994". In A nos 90: Política e Sociedade no Brasil, São Paulo: Brasiliense, 1994.

Patzelt, Werner. "Recruitment and Retention in Western European Parliaments" L egislative Studies Q uarterly, 24 (2): 239-279. 1999.

Pereira, Carlos e Renno, Lucio, "Successful Reelection Strategies in Brazil: The Electoral Impact of Distinct Institutional Incentives." Electoral Studies, 22 (3): 425-448, 2003.

Pereira, Carlos, Timothy Power, e Lucio Renno. "Under What Conditions do Presidents Resort to Decree Power? Theory and Evidence from the Brazilian Case" The J ournal of Politics, 67 (1): 178-200, 2005.

Pereira, Carlos e M uller, Bernardo. "Partidos Fracos na A rena Eleitoral e Partidos Fortes na A rena Legislativa: A Conexão Eleitoral no Brasil". Dados, 46(4): 735-771, 2004.

Rohde, David. 1979. "Risk Bearing and Progressive A mbition: The Case of the M embers of the United States H ouse of Representatives". A merican Journal of Political Science, 23 (1): 1-26.

Samuels, David. "A mbition and Competition: Explaining Legislative Turnover in Brazil". L egislative Studies Q uarterly XXV (3): 481-497, 2000a.

. "The gubernatorial coat-tails effect: Federalism and Congressional elections in Brazil." The Journal of Politics, Vol. 62 (1): 240-253, 2000b.

. "Incumbents and Challengers on a Level Playing Field: A ssessing the Impact of Campaign Finance in Brazil." The J ournal of Politics, 63 (2): 569-584, 2001.

"Pork-Barreling is $\mathrm{N}$ ot Credit-Claiming or Advertising: Campaign Finance and the Sources of the Personal Vote in Brazil." The Journal of Politics, 64 (3): 345-863, 2002.

. A mbition, Federalism, and Legislative Politics in Brazil. Cambridge: Cambridge University Press, 2003.

Santos, Fabiano. "Recruitment and Retention of Legislators in Brazil". L egislative Studies Q uarterly, 24 (2): 209-237. 1999.

Santos, Fabiano e Renno, Lucio. "The Selection of Committee Leadership in the Brazilian Chamber of Deputies". The Journal of Legislative Studies, 10 (1): 50-70, 2004.

Santos, Wanderley G. Sessenta e Q uatro: A natomia da Crise. São Paulo: Vértice Press, 1986.

Stein, Robert e Bickers, Kenneth. "Congressional Elections and the Pork Barrel". The Journal of Politics, 56 (2): 377-399, 1994.

Squire, Peverill. "M ember Career O pportunities and the Internal O rganization of Legislatures". The Journal of Politics, 50 (3): 726-744, 1988.

Swift, Elaine. "The Electoral Connection M eets the Past: Lessons from Congressional H istory, 1789 1899" Political Science Q uarterly, 102 (4): 625-645, 1987. 